\title{
Article \\ Study on the Preparation and Lipophilic Properties of Polyvinyl Alcohol (PVA) Nanofiber Membranes via Green Electrospinning
}

\author{
Jun Cong Ge, Guirong Wu, Sam Ki Yoon * (D), Min Soo Kim * and Nag Jung Choi *(i)
}

Citation: Ge, J.C.; Wu, G.; Yoon, S.K.; Kim, M.S.; Choi, N.J. Study on the Preparation and Lipophilic Properties of Polyvinyl Alcohol (PVA) Nanofiber Membranes via Green Electrospinning. Nanomaterials 2021, 11, 2514.

https://doi.org/10.3390/

nano11102514

Academic Editor: Takuya Kitaoka

Received: 3 September 2021

Accepted: 24 September 2021

Published: 27 September 2021

Publisher's Note: MDPI stays neutral with regard to jurisdictional claims in published maps and institutional affiliations.

Copyright: (c) 2021 by the authors. Licensee MDPI, Basel, Switzerland. This article is an open access article distributed under the terms and conditions of the Creative Commons Attribution (CC BY) license (https:/ / creativecommons.org/licenses/by/ $4.0 /)$.
Division of Mechanical Design Engineering, Jeonbuk National University, Jeonju-si 54896, Korea; jcge@jbnu.ac.kr (J.C.G.); wgr@jbnu.ac.kr (G.W.)

* Correspondence: sky596072@hanmail.net (S.K.Y.); kimms@jbnu.ac.kr (M.S.K.); njchoi@jbnu.ac.kr (N.J.C.)

\begin{abstract}
As an environmentally friendly water-soluble polymer, polyvinyl alcohol (PVA) has attracted extensive attention because of its non-toxic, degradable, low cost, and good biocompatibility. Electrospinning is a kind of nanotechnology, and the nanofiber membrane prepared by it has the advantages of large surface area-to-volume ratios, nano- to micron-sized fibers, etc. Herein, a simple and facile one-step green electrospinning method was developed to fabricate various environmentally friendly PVA nanofiber membranes. The lipophilic properties of PVA membranes were investigated and optimized according different PVA concentrations. The PVA electrospun fiber prepared from the solution at a concentration of $10 \mathrm{wt} \%$ had the highest adsorption capacity for the adsorption of new and waste engine oils, and the waste engine oil adsorption capacity $(12.70 \mathrm{~g} / \mathrm{g})$ was higher than that of new engine oil $(11.67 \mathrm{~g} / \mathrm{g})$. It also has a relatively large BET surface area $\left(12.05 \mathrm{~m}^{2} / \mathrm{g}\right)$, a pore volume $\left(0.04 \mathrm{~cm}^{3} / \mathrm{g}\right)$, and an appropriate pore diameter $(13.69 \mathrm{~nm})$ and fiber diameter $(174.21 \mathrm{~nm})$. All electrospun PVA membranes showed excellent lipophilic properties due to their oil contact angles of much less than $30^{\circ}$. Therefore, PVA electrospun fibrous membranes have great application potential in the field of purifying engine oil due to the excellent lipophilic properties and oil absorption capacity.
\end{abstract}

Keywords: polyvinyl alcohol; green electrospinning; engine oil; lipophilic properties; oil contact angle

\section{Introduction}

Electrospinning, as one of the simplest technologies to prepare nanofibers, has attracted wide attention for many years. Its working principle is that the spinnable polymer is subjected to an electric field force opposite to the direction of surface tension under the action of a high-voltage electrostatic field. When the electric field is strong enough, the spinning precursor is elongated from a spherical shape to a cone shape, that is, Taylor cone, so as to form continuous fibers with diameters ranging from $2 \mathrm{~nm}$ to several micrometers $[1,2]$.

Compared with the traditional filtration membrane, electrospun nanofibrous membranes have large surface area-to-volume ratios, porous structure, and nano- to micronsized fibers, which guarantee the excellent filtering performance [3,4]. The resulting as-spun nanofibers can also be modified by physicochemical methods (e.g., Ball milling and functional group modification) to obtain the desired porosity, pore sizes, and related functional groups [5-7].

Therefore, the electrospun fibers are widely used in filtration [8], ultrafiltration [9], affinity membranes [10], protective clothing [11], scaffolds in tissue engineering [12], enzyme immobilization [13], drug delivery [14], battery materials [15], sensor [16], and other fields [17]. The spinnable materials that are commonly used for electrospinning are polyurethane (PU) [18], polyacrylonitrile (PAN) [19], polyvinyl acetate (PVAc) [20], and polyvinylidene fluoride (PVDF) [21]. However, most of these commonly used polymers 
need to be dissolved in organic solvents, such as $\mathrm{N}, \mathrm{N}$-dimethylformamide (DMF), to prepare spinning precursors. DMF is a harmful solvent and raises severe concerns in production with respect to environmental and safety issues.

Therefore, it is necessary to find a new preparation method of nanofiber membranes. Recently, green electrospinning using an aqueous solution as the solvent has attracted great attention [22]. Polyvinyl alcohol (PVA) is a water-soluble polyhydroxy polymer, which is selected as the fiber precursor for filtering oil and has great application potential [23]. In recent years, using PVA as a hot spinning material has attracted substantial attention due to its cleanliness, safety, excellent chemical resistance, thermal stability, biodegradability, and the capability to be easily modified through its hydroxylic groups [24-26].

Pisuchpen et al. modified PVA fiber with multiple cycles of $\mathrm{SiCl}_{4} / \mathrm{H} 2 \mathrm{O}$ treatment and silanization by electrospinning technology, which provides excellent water adhesion (the petal effect) [27]. Zhu et al. [28] mixed chitosan, $\mathrm{SiO}_{2} \mathrm{NPs}, \mathrm{AgNO}_{3}$, and PVA polymer, in turn, and finally prepared an environment-friendly multifunctional electrospun air filtration membrane with antibacterial properties and the ability to filter aerosol particles.

Cui et al. [22] fabricated PVA/sodium lignosulfonate (LS) composite nanofiber membranes via green electrospinning. They reported that the addition of LS helped increase the PM2.5 removal efficiency compared to that of a pure PVA nanofiber membrane. Pervez et al. prepared the water soluble chitosan/polyvinyl alcohol (WSCHT/PVA) nanofiber at different mass ratios by using green electrospinning, and water was used as an ecofriendly solvent, and genipin was used as a nontoxic cross-linker. The composite membrane with 20/80 blend ratio had the most optimum uniform fiber morphology [29].

Other researchers have also studied the modifiable properties of PVA nanofiber membranes and optimized their ability to filter air and aqueous solution [30,31]. However, most studies focus on improving the hydrophilicity of the PVA electrospun membranes rather than enhancing the lipophilicity. The optimization of the lipophilic properties of PVA membranes is helpful to remove harmful substances in oil or realize oil-water separation [32].

To date, a pure PVA nanofibrous membrane has yet not been reported to have lipophilic properties according to the concentration of polymer. Therefore, this study mainly investigated the fabrication, characterization, and lipophilic properties of PVA membranes and optimized the PVA concentration on fiber morphology and lipophilic properties. An interesting result is that the PVA membrane exhibited excellent lipophilicity, which may enlarge the potential applications in the field of waste oil treatment.

\section{Materials and Methods}

\subsection{Materials}

Polyvinyl alcohol (PVA) with $80,000 \mathrm{~g} / \mathrm{mol}$ of weight molecular weight (Mw) was used as the main material for fabricating the environmentally-friendly fiber membrane and was obtained from Hefei Sipin Technology Co., Ltd., Hefei, China. Pure water (conductivity: Max. $2.0 \mu \mathrm{s} / \mathrm{cm}$; resistivity: Min. $0.5 \mathrm{M} \Omega$ ) was used as the solvent and was procured from Samchun Pure Chemical Co., Ltd., Pyeongtaek-si, Korea. The oil samples included new and waste diesel engine oil, which were $5 \mathrm{~W} 30$ synthetic oil, and their viscosities were $247.96 \mathrm{cP}$ and $281.10 \mathrm{cP}$, respectively. The new and waste $5 \mathrm{~W} 30$ synthetic engine oils were offered by Hyundai Oilbank Co., Ltd., Seoul, Korea.

\subsection{Fabrication of the PVA Nanofiber Membrane}

To observe the membrane-forming characteristics of the PVA fiber and obtain the best mixing ratio, a variety of PVA/water electrospinning solutions $(8 \mathrm{wt} \%, 9 \mathrm{wt} \%, 10 \mathrm{wt} \%$, $11 \mathrm{wt} \%, 12 \mathrm{wt} \%, 13 \mathrm{wt} \%, 14 \mathrm{wt} \%$, and $15 \mathrm{wt} \%$ ) were prepared. The spinning process took about $8 \mathrm{~h}$. The details are as follows: First, in order to obtain the initial spinning precursor of PVA, eight PVA powders with different mass fractions were respectively dissolved in the prepared pure water using a magnetic stirrer and dissolved for $24 \mathrm{~h}$ at room temperature. 
Then, to obtain a homogeneous PVA spinning precursor, these initial spinning precursors were treated with ultrasonication for $2 \mathrm{~h}$. Finally, the prepared PVA electrospinning solutions were injected into a $12 \mathrm{~mL}$ syringe with a $0.5 \mathrm{~mm}$ inner diameter needle (21G) to prepare for spinning. All as-prepared spinning solutions were electrospun under $20 \mathrm{kV}$ of high-voltage electricity with a $100 \mathrm{~mm}$ tip-to-collector distance with a solution feed rate of $0.5 \mathrm{~mL} / \mathrm{h}$. The schematic diagram of electrospinning system is shown in Figure 1 .

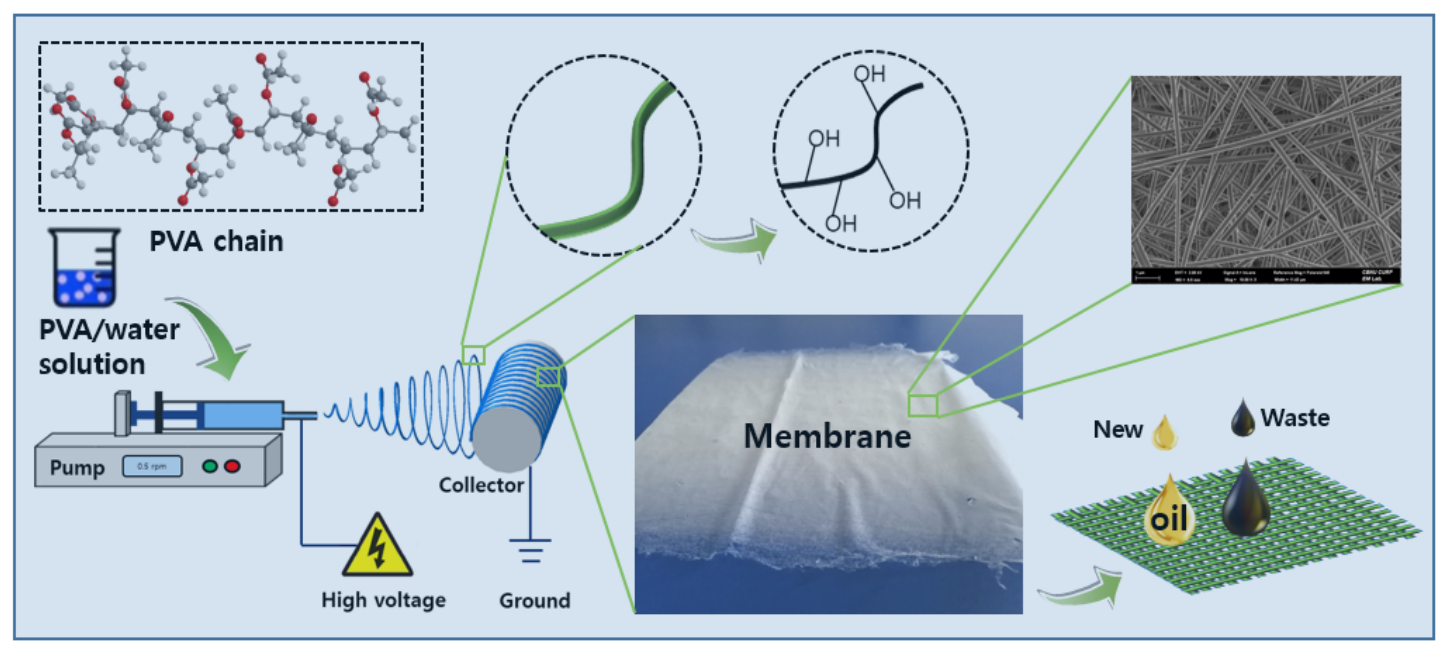

Figure 1. Schematic diagram of the electrospinning system.

\subsection{Viscosity and Conductivity Measurements}

The viscosities of the electrospun PVA solutions and oils were measured at $20{ }^{\circ} \mathrm{C}$ by a rotational viscometer (Viscolead One, Fungilab SA, Barcelona, Spain) using an L3-rotor at different rotational speeds (10-100 rpm). The conductivities of the electrospun solutions were determined at $20^{\circ} \mathrm{C}$ by a digital conductivity meter (Starter 300C, Ohuas, Parippany, NJ, USA). The conductivity meter was pre-calibrated using conductivity standard solutions of 84,1413 , and $12,880 \mu \mathrm{S} / \mathrm{cm}$ at $298 \mathrm{~K}$ before starting to record data. All experiments were performed five times, and the average values were taken for the final results.

\subsection{Characterization of the PVA Nanofiber Membrane}

The surface structural morphologies of eight as-prepared electrospun PVA nanofiber membranes were observed with field emission scanning electron microscopy (FE-SEM, Supra 40VP, Carl Zeiss, Jena, Germany) at $2.0 \mathrm{kV}$ and biological transmission electron microscopy (Bio-TEM, Hitachi Tem H-7650, Hitachi, Ltd., Tokyo, Japan) at $100 \mathrm{kV}$. The diameter distribution of the PVA fibers was measured by ImageJ software by measuring 50 randomly selected fibers. The structure and crystal phase of the as-prepared PVA fibrous membranes were analyzed by a multi-purpose high-performance $X$-ray diffractometer (XRD, PANalytical, Eindhoven, The Netherlands) with $\mathrm{Cu} K \alpha(\lambda=1.540 \AA)$ radiation.

The chemical compositions of the as-prepared PVA fibrous membranes were analyzed by Fourier-transform infrared spectroscopy (FT-IR, Spectrum GX, PerkinElmer, Inc., Billerica, MA, USA) in transmittance, with a range of $400-4000 \mathrm{~cm}^{-1}$ and a resolution of $1 \mathrm{~cm}^{-1}$. The surface area, pore size, pore size distribution, pore volume, and other pore properties of the PVA membranes were measured using a surface area and ore size analyzer (BELSORP-max, MicrotracBEL Corp., Osaka, Japan) with nitrogen $\left(\mathrm{N}_{2}\right)$ adsorption-desorption isotherms at $77 \mathrm{~K}$ under high vacuum.

Before measuring the adsorption isotherms of $\mathrm{N}_{2}$ on the samples, the PVA membranes were degassed at $373 \mathrm{~K}$ for $24 \mathrm{~h}$ under vacuum to remove impurities on their surfaces. The multiple-point Brunauer-Emmett-Teller (BET) method and Horvaih-Kawazoe (HK) theory were employed to calculate the specific surface area and pore size distribution, respectively. The total pore volume was calculated at a relative pressure of $\mathrm{P} / \mathrm{P} 0=0.990$. 


\subsection{Oil Adsorption Behavior Experiment}

To investigate the adsorption behavior of the PVA membrane with different PVA concentrations on oil and explore the lipophilic properties, new and waste diesel engine oils were selected as the test objects. Respective $0.01 \mathrm{~g}$ samples of PVA membranes were put into a $50 \mathrm{~mL}$ falcon tube containing $20 \mathrm{~mL}$ of oil. The oil adsorption behavior experiment was carried out at $25^{\circ} \mathrm{C}$ and $200 \mathrm{rpm}$ in a shaking incubator (C-SKI, Chang Shin Scientific Co., Seoul, Korea) for $24 \mathrm{~h}$. After adsorption for $24 \mathrm{~h}$, the PVA membrane was removed from the oil bath and drained for $1 \mathrm{~min}$ to remove the residual oil on the material surface. The oil adsorption capacity of each PVA membrane was determined by the following equation [33]:

$$
Q=\frac{m_{a}-m_{0}}{m_{0}}
$$

where $Q(\mathrm{~g} / \mathrm{g})$ represents the oil adsorption capacity, $m_{a}$ is the total mass of the wet sorbent after $24 \mathrm{~h}$ of oil absorption followed by $1 \mathrm{~min}$ of draining, and $m_{0}$ is the mass of the sorbent before the adsorption experiment. In order to reduce the error caused by the operations, each sample was measured at least three times.

\subsection{Oil Contact Angle Measurement}

The contact angle (CA) formed between the as-prepared electrospun PVA nanofiber membrane and oil was measured by a contact angle analyzer (UNI-CAM/M, GIT software Tech., Ansan-si, South Korea). The CA was determined by the Young-Laplace model and its value was averaged at six different locations in the sample using ImageJ software. The oil sorption behavior of the PVA membranes for new diesel engine oil and waste diesel engine oil can be simply and quickly investigated by observing the change of the oil contact angle.

\section{Results}

\subsection{Physicochemical Properties of the Electrospun Fibrous Mat}

To study the effect of PVA concentration on the fiber morphology and to optimize the mixing ratio, $8 \mathrm{wt} \%, 9 \mathrm{wt} \%, 10 \mathrm{wt} \%, 11 \mathrm{wt} \%, 12 \mathrm{wt} \%, 13 \mathrm{wt} \%, 14 \mathrm{wt} \%$, and $15 \%$ PVA solutions were first electrospun. Figure 2 shows the field emission scanning electron microscopy (FE-SEM) images of the electrospun PVA fibers according to different PVA concentrations. As shown in Figure 2, the PVA fibers are arranged crosswise to each other, randomly distributed on the collected final mat and forming a non-woven network. Further, the PVA fiber surface does not seem to be very smooth due to the presence of some linear grooves (see Figure 2a, inset).

These random crossover permutations form a large number of interconnected voids/ porous structures between the fibers. The interconnected voids/porous structures are helpful for the adsorption effect because they provide more adsorption sites. In addition, it can be clearly seen that different PVA concentrations have a significant effect on the mean fiber diameters and other morphological characteristics. However, when the concentration of PVA exceeds $14 \mathrm{wt} \%$, the nanofibrous structures of the PVA membranes are difficult to maintain due to their contraction, agglomeration, and adhesion between the fibers during the electrospinning process.

A few spider-web-like structures (see Figure $2 \mathrm{~h}$, inset) are found in the $15 \mathrm{wt} \%$ PVA fibrous membranes. A high magnification shows that this spider-web-like fiber is grown from the main PVA nanofibers. The reason for the formation of this PVA spider-web-like structure may be related to the presence of PVA particles, because some PVA particles are not completely dissolved when excess PVA particles are added to water. This is consistent with the research results of other researchers [34]. The higher the viscosity of PVA spinning solution, the easier it is to form a spider web, as high viscosity may delay the thin film area to be evaporated properly. 


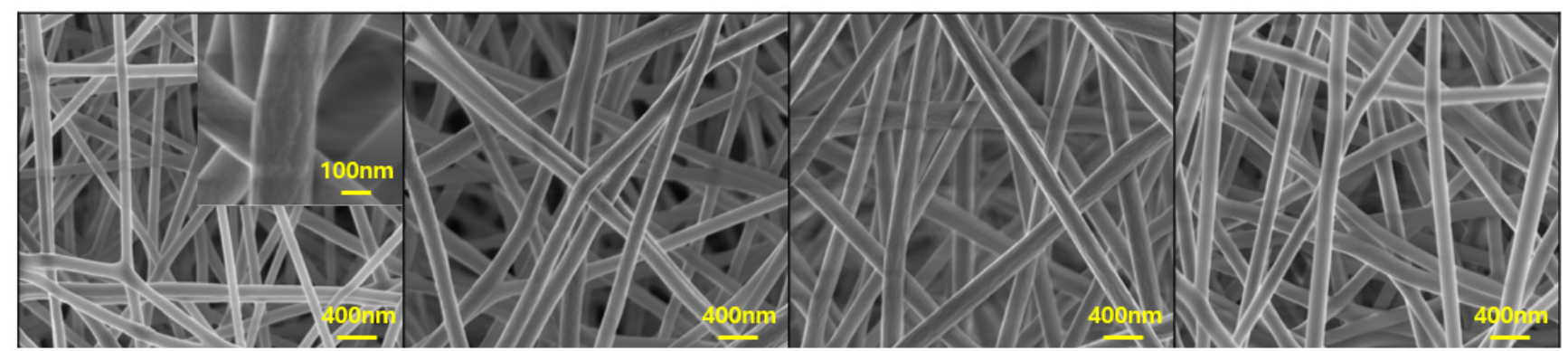

(a)

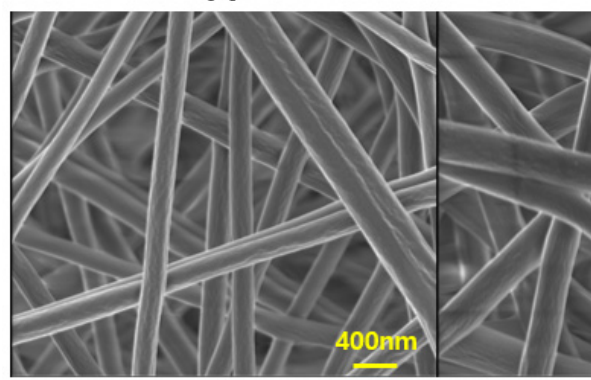

(e) (b) (d)

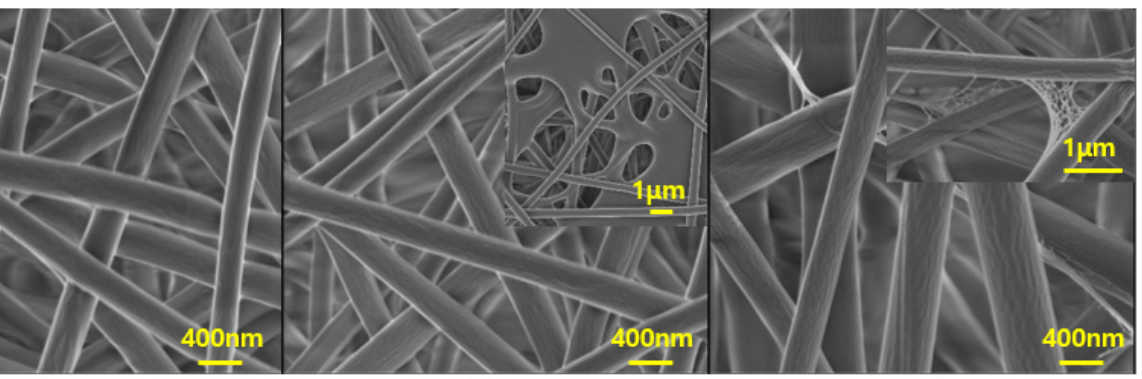

(g)

(h)

Figure 2. FE-SEM images of PVA fibers with various PVA solution concentrations: (a) $8 \mathrm{wt} \%$, (b) $9 \mathrm{wt} \%$, (c) $10 \mathrm{wt} \%$, (d) $11 \mathrm{wt} \%$, (e) $12 \mathrm{wt} \%$, (f) $13 \mathrm{wt} \%$, (g) $14 \mathrm{wt} \%$, (h) $15 \mathrm{wt} \%$.

Table 1 lists several important morphological characteristics of the PVA membrane, including the viscosity and conductivity of the PVA solution, fiber diameter, pore diameter, pore volume, and BET surface area. As shown in Table 1, the viscosity of the PVA solution clearly increases with the increase of the concentration of PVA in water, while the conductivity of the PVA solution shows a broadly increasing trend with increasing concentration. The thickness of PVA membrane increased with the increase of PVA concentration.

Table 1. Physical properties of the spinning solutions and electrospun fibrous membranes.

\begin{tabular}{|c|c|c|c|c|c|c|c|c|}
\hline $\begin{array}{l}\text { PVA } \\
\text { Solutions } \\
\text { (\%) }\end{array}$ & $\begin{array}{l}\text { Viscosity } \\
\text { (cP) }\end{array}$ & $\begin{array}{l}\text { Conductivity } \\
(\mu \mathrm{S} / \mathrm{cm})\end{array}$ & $\begin{array}{c}\text { Mean } \\
\text { Fiber } \\
\text { Diameter } \\
(\mathrm{nm})\end{array}$ & $\begin{array}{l}\text { Mean Pore } \\
\text { Diameter } \\
(\mathrm{nm})\end{array}$ & $\begin{array}{l}\text { Total Pore } \\
\text { Volume } \\
\left(\mathrm{cm}^{3} / \mathrm{g}\right)\end{array}$ & $\begin{array}{c}\text { BET } \\
\text { Surface } \\
\text { Area } \\
\left(\mathrm{m}^{2} / \mathrm{g}\right)\end{array}$ & $\begin{array}{c}\text { Thickness } \\
\text { (mm) }\end{array}$ & $\begin{array}{c}\text { Bulk Density } \\
\left(\mathrm{cm}^{3} / \mathrm{g}\right)\end{array}$ \\
\hline $8 \%$ & $241.34 \pm 3.33$ & $485.8 \pm 1.92$ & $95.28 \pm 12.05$ & 11.84 & 0.06 & 19.58 & 0.10 & 4.50 \\
\hline $9 \%$ & $457.24 \pm 8.17$ & $534.2 \pm 1.10$ & $126.07 \pm 26.65$ & 19.87 & 0.04 & 8.88 & 0.11 & 2.04 \\
\hline $10 \%$ & $655.4 \pm 6.50$ & $571.8 \pm 5.17$ & $174.21 \pm 23.57$ & 13.69 & 0.04 & 12.05 & 0.12 & 2.77 \\
\hline $11 \%$ & $1101.84 \pm 16.82$ & $608.2 \pm 1.30$ & $147.91 \pm 20.93$ & 13.08 & 0.03 & 9.31 & 0.18 & 2.14 \\
\hline $12 \%$ & $1602.94 \pm 31.19$ & $599 \pm 4.18$ & $190.66 \pm 22.84$ & 9.33 & 0.02 & 9.33 & 0.19 & 2.14 \\
\hline $13 \%$ & $2056.52 \pm 33.73$ & $674.6 \pm 2.70$ & $266.70 \pm 30.61$ & 11.01 & 0.02 & 7.93 & 0.20 & 1.82 \\
\hline $14 \%$ & $3615.84 \pm 27.77$ & $621.8 \pm 1.30$ & $308.92 \pm 33.74$ & 12.69 & 0.02 & 7.58 & 0.21 & 1.74 \\
\hline $15 \%$ & $5845.16 \pm 69.42$ & $663.8 \pm 5.89$ & $479.46 \pm 40.60$ & 17.30 & 0.02 & 5.06 & 0.22 & 1.16 \\
\hline
\end{tabular}

The average fiber diameters were measured as $95.28 \pm 12.05 \mathrm{~nm}, 126.07 \pm 26.65 \mathrm{~nm}$, $174.21 \pm 23.57 \mathrm{~nm}, 147.91 \pm 20.93 \mathrm{~nm}, 190.66 \pm 22.84 \mathrm{~nm}, 266.70 \pm 30.61 \mathrm{~nm}, 308.92 \pm 33.74 \mathrm{~nm}$, and $479.46 \pm 40.60 \mathrm{~nm}$ from the $8 \mathrm{wt} \%, 9 w \mathrm{t} \%, 10 \mathrm{wt} \%, 11 \mathrm{wt} \%, 12 \mathrm{wt} \%, 13 \mathrm{wt} \%, 14 \mathrm{wt} \%$, and $15 \mathrm{wt} \%$ PVA solutions, respectively. The average fiber diameters and average pore diameters of eight PVA fibers ranged from 95 to $480 \mathrm{~nm}$ and 9 to $20 \mathrm{~nm}$, respectively. These nanoscale fibers diameters and pore sizes are beneficial to increase the specific surface area of the fibers, thus, increasing the adsorption and adhesion ability of oil on the fiber surface [35].

With the increase of PVA concentration in water, the mean diameter of the PVA fiber first increased when the PVA concentration was between $8 \mathrm{wt} \%$ and $10 \mathrm{wt} \%$, then decreased at $11 \mathrm{wt} \%$, and increased again between $12 \mathrm{wt} \%$ and $15 \mathrm{wt} \%$. This is mainly related to the comprehensive effect of viscosity and the conductivity of the PVA solution. The solution parameters, including viscosity and conductivity, play an important role regarding the fiber morphology (i.e., fiber diameter and structure) in the electrospinning process. In general, a 
higher viscosity and lower conductivity of the spinning solution hinder further stretching of the fiber, resulting in large-diameter nanofibers [36].

On the whole, in this study, the viscosity of PVA spinning solution plays a greater role than the conductivity in determining whether the fiber diameter becomes larger or smaller. This is because the increase of viscosity of PVA spinning solution is much greater than that of conductivity. The higher viscosity hinders the flow and elongation of spinning precursor, resulting in less stretched jet and increasing fiber diameter [37]. Moreover, different concentrations of the PVA spinning solution also have significant effects on the BET surface area and total pore volume in Table 1.

The membrane containing $8 \mathrm{wt} \%$ PVA shows the highest BET surface area of $19.58 \mathrm{~m}^{2} / \mathrm{g}$ and a total pore volume of $0.06 \mathrm{~cm}^{3} / \mathrm{g}$, while the $15 \mathrm{wt} \%$ PVA shows the lowest BET surface area of $5.06 \mathrm{~m}^{2} / \mathrm{g}$ and a total pore volume of $0.02 \mathrm{~cm}^{3} / \mathrm{g}$. The change trend of bulk density is the same as that of BET. Although the decrease in fiber diameter is a factor to increase the fiber surface area, it can be concluded from the current results that variation of the BET surface area does not completely depend on the fiber diameter when the fiber diameter changes in a small range $(<50 \mathrm{~nm})$.

Figure 3 shows the PVA fiber diameter distribution according to different PVA concentrations. With an increase in PVA concentration, the average diameter of all fibers increased significantly compared with the $8 \mathrm{wt} \%$ sample. Most of the fiber diameters of the $8 \mathrm{wt} \%$ PVA are in the range of $90-100 \mathrm{~nm}$, with a narrow diameter distribution. A somewhat broader distribution of other fiber diameters is observed when the PVA concentration exceeds $8 \mathrm{wt} \%$. The $10 \mathrm{wt} \%$ and $11 \mathrm{wt} \%$ PVA fiber diameter distributions are more concentrated, in the range of about $120-180 \mathrm{~nm}$. Overall, there is a nanometer-scale diameter distribution of all the PVA fibers, and the largest diameter of fibers does not exceed $850 \mathrm{~nm}$.

In this study, the concentration of PVA was used as the main variable, its influence on the viscosity and conductivity of the spinning precursor was investigated, and the fiber morphology was analyzed according to PVA concentration. In fact, in addition to the viscosity and conductivity of the spinning solution, some spinning parameters, such as applied voltage, tip-to-collector distance, flow rate, and needle diameter also affect the fiber morphology during the spinning process [38].

Appropriately increasing the voltage [39] and tip-to-collector distance [40], reducing the flow rate [41] are conducive to the stretching of spinning fiber and the evaporation of solvent to form small-diameter nanofibers. Most researchers have reported that the viscosity and conductivity of spinning precursors play the most important role in the influence of fiber morphology, compared with other spinning parameters [42]. Therefore, the operating parameters, such as applied voltage, tip-to-collector distance and flow rate, re optimized before the preparation of the PVA nanofiber membrane in this study.

EDS spectra of a $10 \mathrm{wt} \%$ PVA membrane is shown in Figure 4. As shown in Figure 4, except for the signals of carbon and oxygen elements, no other signals of impurities were found, indicating that the PVA spinning solution was not polluted by the surrounding environment during the spinning process.

Figure 5 shows the TEM images of a series of samples with different PVA concentrations. The PVA fibers are very homogenous in morphology and display a randomly distributed and interweaved to form a network. As shown in Figure 5a,b, some beaded fibers can be clearly observed when the concentration of the PVA spinning solution is low (i.e., 8 and $9 \mathrm{wt} \%$ ). The fiber morphology is changed from a beaded fiber to a uniform fiber structure with increasing PVA concentration.

This is mainly due to reduced chain entanglement in the spinning solution with a lower concentration, which leads to the contraction of the diameters of the jet and leads to jet instability of the polymer solution. Properly increasing the concentration of the spinning solution is beneficial to enhancing the stability of the polymer solution. However, the spinning effect is not very effective when the PVA concentration exceeds $14 \mathrm{wt} \%$, as shown in Figure 5g,h. 

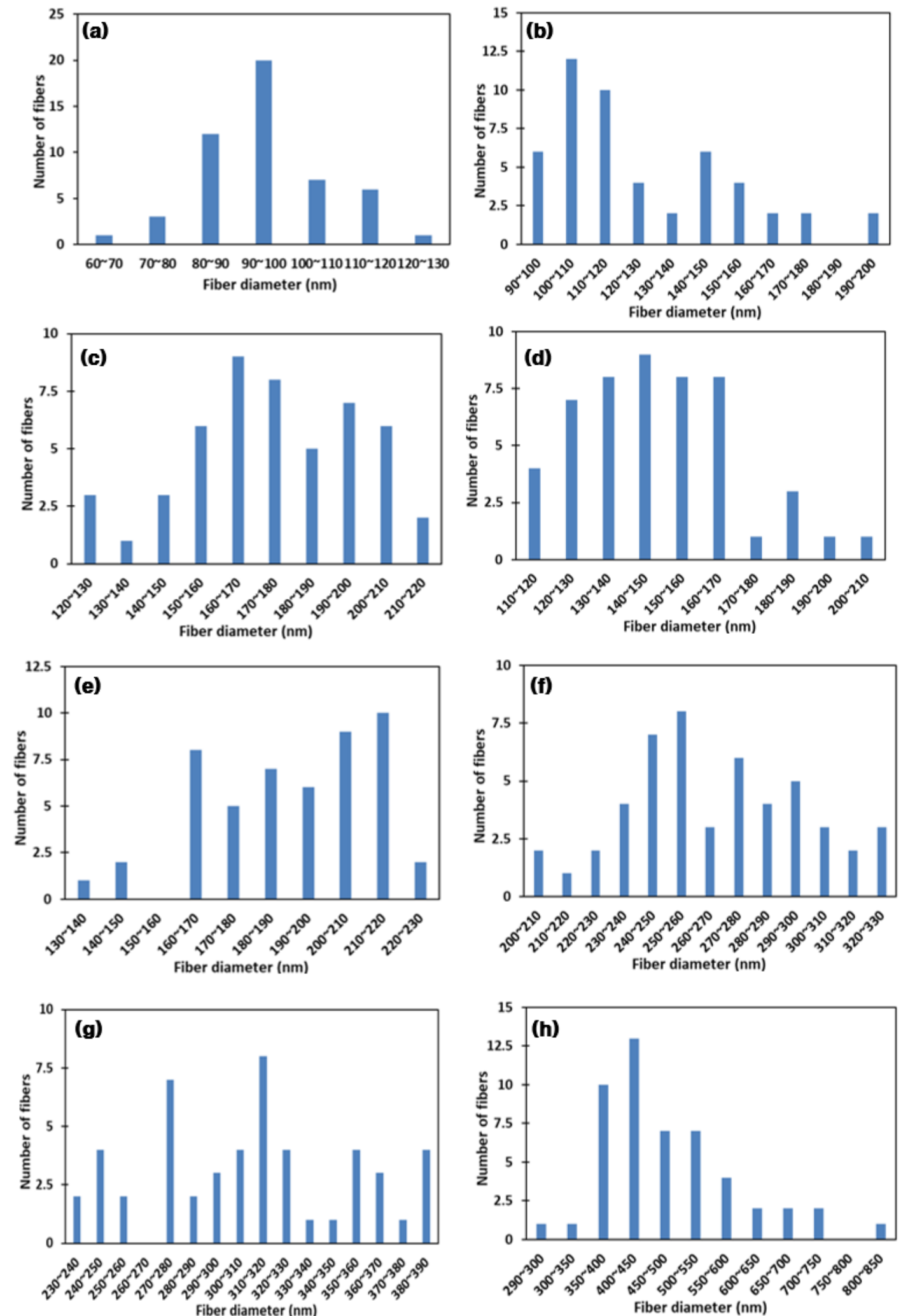

Figure 3. The fiber diameter distributions with various PVA solution concentrations: (a) $8 w t \%$, (b) $9 w t \%$, (c) $10 w t \%$, (d) $11 \mathrm{wt} \%$, (e) $12 \mathrm{wt} \%$, (f) $13 \mathrm{wt} \%$, (g) $14 \mathrm{wt} \%$, and (h) $15 \mathrm{wt} \%$. 


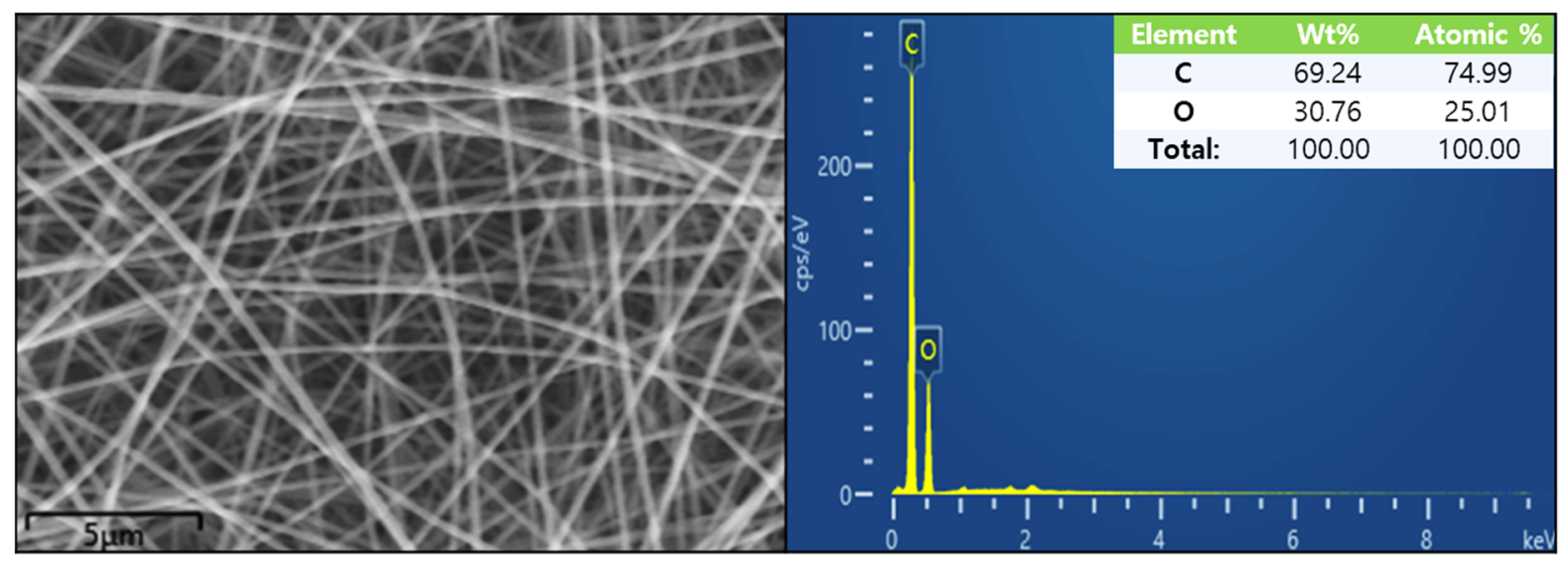

Figure 4. EDS spectra of PVA fibers prepared from the PVA solution at concentration of $10 \mathrm{wt} \%$.

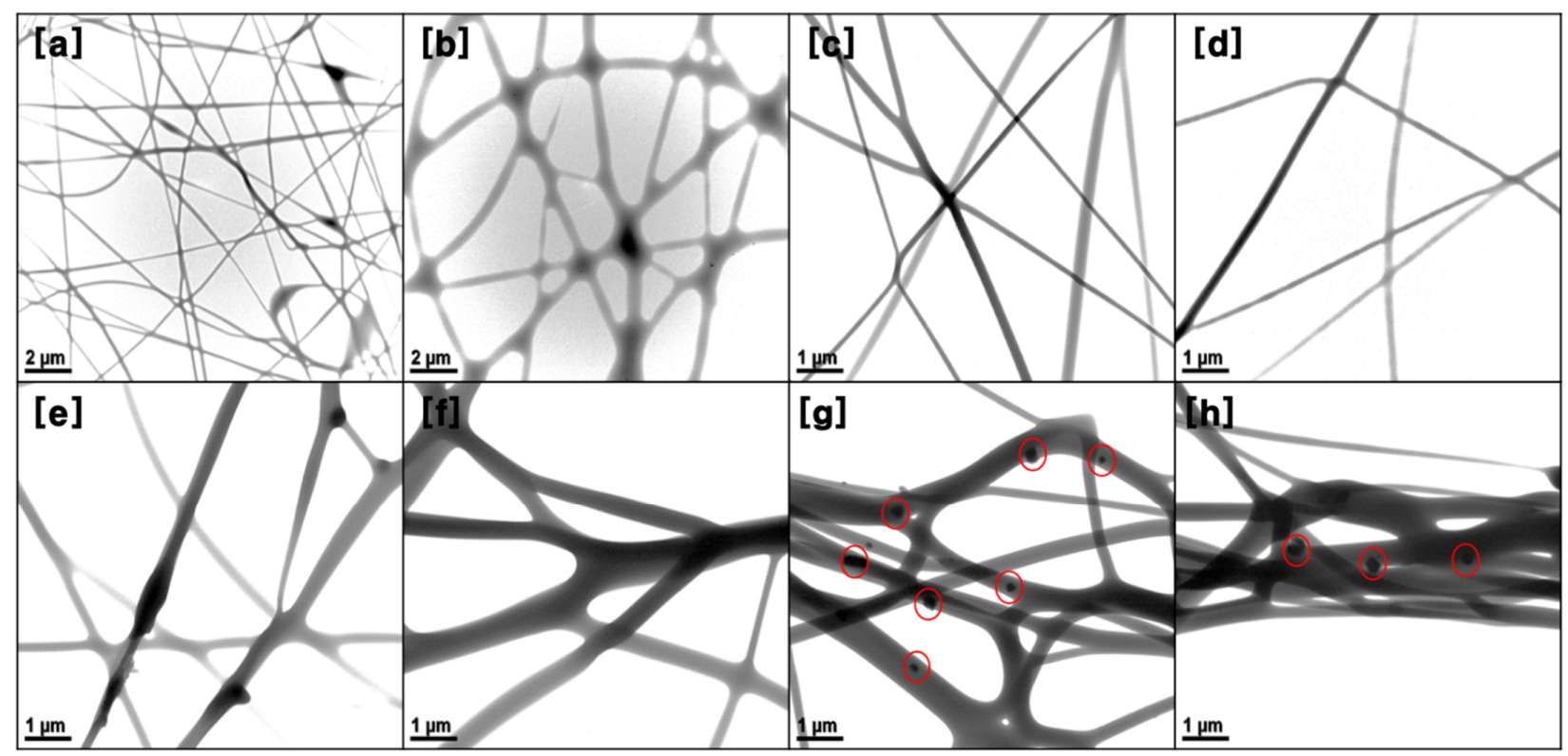

Figure 5. Bio-TEM images of PVA fibers with various PVA solution concentrations: (a) $8 \mathrm{wt} \%$, (b) $9 \mathrm{wt} \%$, (c) $10 \mathrm{wt} \%$, (d) $11 \mathrm{wt} \%$, (e) $12 \mathrm{wt} \%$, (f) $13 \mathrm{wt} \%$, (g) $14 \mathrm{wt} \%$, and (h) $15 \mathrm{wt} \%$.

When the concentration of PVA exceeds $14 \mathrm{wt} \%$, large diameter fibers are formed, fibers adhere together and many PVA particles appear in/on the surface of PVA fibers. This is because the inter- and intra-chain bonds between polar hydroxyl groups (-OH) of PVA molecules are not easily activated, which makes it difficult to form a liquid jet when the concentration of the spinning solution is too high [43]. Therefore, it is necessary to select the appropriate concentration of spinning solution for the formation of continuous and uniform fibers. Similar results were also reported by Zhang et al. [44]. They also indicated that, to obtain a large number of chain entanglements in the electrospinning process, the concentration of polymer solution must exceed a critical concentration.

Figure 6 shows the nitrogen $\left(\mathrm{N}_{2}\right)$ adsorption and desorption isotherm and BarretJoyner-Halender (BJH) pore size distribution. The $\mathrm{N}_{2}$ adsorption-desorption method and $\mathrm{BJH}$ are common methods to investigate the pore structure and pore size distribution for fiber membrane materials. The pore structure characteristics of PVA nanofibrous membranes were obtained by the $\mathrm{N}_{2}$ adsorption-desorption measurements at $77 \mathrm{~K}$. In Figure 6a, the adsorption isotherms of PVA membranes combine type I and type II characteristics, as there is a weak hystersis loop between the adsorption and desorption branches. 

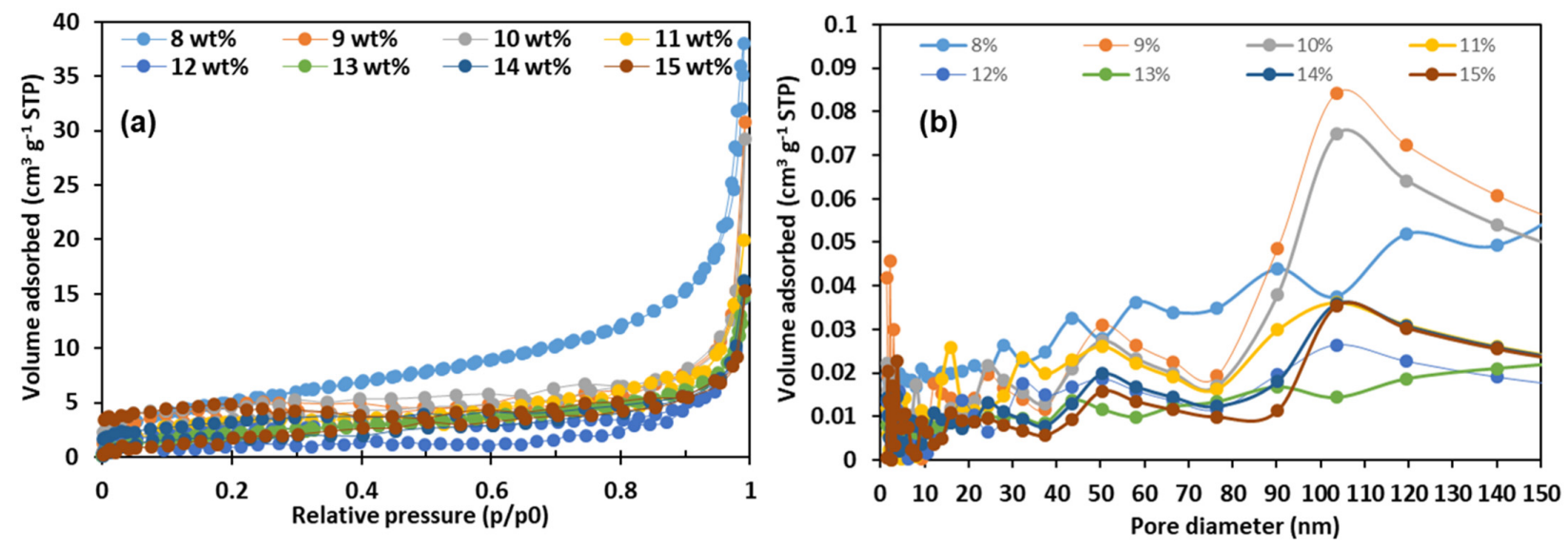

Figure 6. Nitrogen adsorption-desorption isotherms (a), and BJH adsorption pore size distribution (b) for all samples.

In addition, it can be observed that these PVA membranes with low concentrations $\left(<11 \mathrm{wt} \%\right.$ ) have large quantities adsorbed of $\mathrm{N}_{2}$, above $20 \mathrm{~cm}^{3} / \mathrm{g}$, of which the highest value can reach up to $37.97 \mathrm{~cm}^{3} / \mathrm{g}$ at high relative pressure $(\mathrm{P} / \mathrm{P} 0)$ range (approaching 1.0), which indicates the existence of large mesopores and macropores [45]. In Figure 6b, the pore size distribution was calculated by the $\mathrm{BJH}$ method from the adsorption isotherm. As shown in Figure 6b, many peaks can be clearly observed, which indicates that the pore size distribution of PVA fiber membrane is not very uniform, including micropores (diameters $<2 \mathrm{~nm}$ ), mesopores (diameters $2-50 \mathrm{~nm}$ ), and macropores (diameters $>50 \mathrm{~nm}$ ) [46].

\subsection{XRD and FT-IR Analysis}

X-ray diffraction and FT-IR are often used to determine changes in microstructure and assess the chemical groups of polymers and their composites, respectively. Figure 7 depicts the XRD spectrum and FT-IR spectra for various fibers according to different PVA concentrations. As shown in Figure 7a, there is a strong diffraction peak appearing around $2 \theta=19.2^{\circ}$, which is attributed to the (101) plane of PVA semicrystalline structures in the PVA fibers due to the occurrence of strong inter- and intra-molecular hydrogen bonding $[47,48]$. The intensity of this diffraction peak first increases and then decreases (from $13 \mathrm{wt} \%$ to $15 \mathrm{wt} \%$ ) with the increase of PVA concentration.
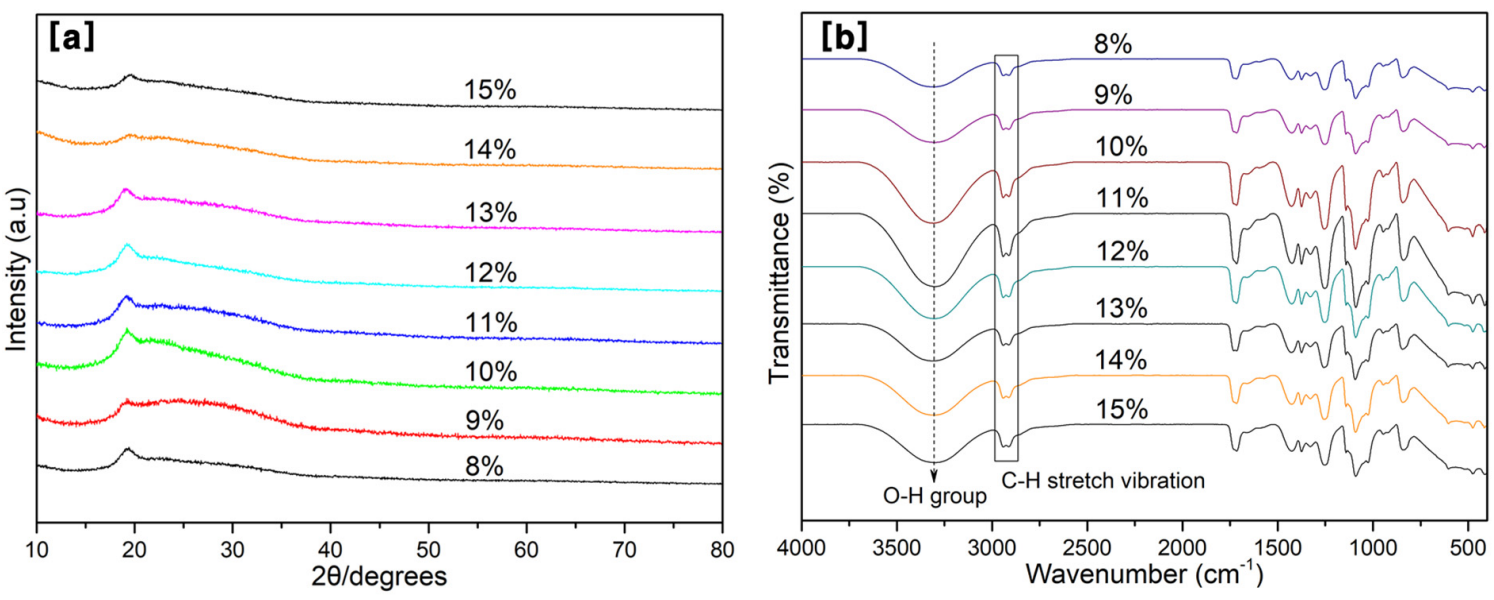

Figure 7. XRD (a) and FT-IR (b) analysis for all PVA membranes.

This may be due to the excessive addition of PVA, resulting in conditions under which the fiber cannot be well spun, forming more polymerization, thus, reducing the crystallinity of the PVA. Increasing the PVA content appropriately is beneficial to the crystallinity, which has been reported by other researchers [49]. The XRD results also support the fiber-forming 
properties of the PVA solution. Kurd et al. [48] reported that the crystal structure is related to the properties of the polymer (molecular weight), process parameters (applied voltage and flow rate), and solvent medium (evaporation rate and polymer-solvent interaction).

As shown in Figure 7b, it can be clearly seen that the major characteristic peaks of the PVA membrane were observed at around 3305, 2943, 2910, 1716, 1420, 1371, 1146, 1092, and $838 \mathrm{~cm}^{-1}$. The peak at $3305 \mathrm{~cm}^{-1}$ is attributed to the $\mathrm{O}-\mathrm{H}$ stretching vibration from the intermolecular and intramolecular hydrogen bonds, while the peaks at 2943 and $2910 \mathrm{~cm}^{-1}$ can be assigned to the $-\mathrm{CH}_{2}$ - stretching vibration from methylene groups and the $\mathrm{C}-\mathrm{H}$ stretching vibration from alkyl groups, respectively.

The peak at $1716 \mathrm{~cm}^{-1}$ belongs to the $\mathrm{C}=\mathrm{O}$ carbonyl stretch from acetate groups, while the peaks around 1420,1371,1146, 1092, and $838 \mathrm{~cm}^{-1}$ are assigned to the $\mathrm{C}-\mathrm{H}$ bending vibration of $\mathrm{CH}_{2}, \mathrm{C}-\mathrm{H}$ deformation vibration, $\mathrm{C}-\mathrm{O}-\mathrm{C}$ asymmetric stretching, $\mathrm{C}-\mathrm{O}$ stretching of acetyl groups, and the $\mathrm{C}-\mathrm{C}$ stretching vibration, respectively [50-52]. The specific wave number and vibration type are shown in Table 2. Similar to the results of $\mathrm{XRD}$, the intensity of FTIR also shows a trend of first increasing and then decreasing with the increase of PVA concentration.

Table 2. Main FTIR peaks for the PVA nanofiber membrane.

\begin{tabular}{ccc}
\hline Wave Number $\mathbf{( \mathbf { c m } ^ { - 1 } )}$ & Vibration Type & Assignment \\
\hline 3305 & stretching vibration & $\mathrm{O}-\mathrm{H}$ \\
2943 & stretching vibration & $-\mathrm{CH}_{2}-$ \\
2910 & stretching vibration & $\mathrm{C}-\mathrm{H}$ \\
1716 & carbonyl stretch & $\mathrm{C}=\mathrm{O}$ \\
1420 & bending vibration & $\mathrm{C}-\mathrm{H}$ \\
1371 & deformation vibration & $\mathrm{C}-\mathrm{H}$ \\
1146 & asymmetric stretching, & $\mathrm{C}-\mathrm{O}-\mathrm{C}$ \\
1092 & stretching & $\mathrm{C}-\mathrm{O}$ \\
838 & stretching vibration & $\mathrm{C}-\mathrm{C}$ \\
\hline
\end{tabular}

\subsection{Oil Adsorption Capacity}

To investigate the oil adsorption capacity of all PVA membranes for the adsorption of new and waste diesel engine oils, the adsorption test was carried out at $25^{\circ} \mathrm{C}$ and $200 \mathrm{rpm}$ in a shaking incubator for $24 \mathrm{~h}$. Figure 8 exhibits the oil adsorption capacity of all PVA membranes. The oil adsorption capacities of these PVA membranes were far less than those of an electrospun porous polystyrene (PS) membrane (about $900 \mathrm{~g} / \mathrm{g}$ adsorption for oil) reported by [33]. Therefore, the optimized PVA membrane in this work has great potential to be applied to vehicle filters, such as fuel filters and oil filters. As a whole, the adsorption capacity of PVA membranes for the two oils increased first and then decreased with an increase of PVA concentration.

The $10 \mathrm{wt} \%$ PVA membrane has the largest adsorption capacity for the two oils compared with other membranes. In addition, when the concentration of the PVA is between $8 \mathrm{wt} \%$ and $11 \mathrm{wt} \%$, the adsorption capacity of the PVA membrane for waste engine oil is significantly greater than that for new engine oil. The adsorption capacities of the $12 \mathrm{wt} \%$ and $13 \mathrm{wt} \%$ PVA membranes for the two oils are almost the same. With the continued increase in the concentration of PVA to $14 \mathrm{wt} \%$ and $15 \mathrm{wt} \%$, the adsorption capacity of the PVA membrane for two oils is reduced, and the adsorption capacity for new engine oil is higher than that for waste engine oil.

Generally speaking, the thinner the fiber, the greater the porosity and BET surface area of the electrospun membrane, and the higher the adsorption capacity for the adsorption of the adsorbate. These advantages can provide more adsorption sites [53]. However, through the current research results, we found that, although the $8 \mathrm{wt} \%$ PVA membrane has the smallest fiber diameter $(95.28 \mathrm{~nm})$ and the largest pore volume $\left(0.06 \mathrm{~cm}^{3} / \mathrm{g}\right)$ and BET surface area $\left(19.58 \mathrm{~m}^{2} / \mathrm{g}\right)$ compared to other samples, the existence of a smaller pore diameter $(11.84 \mathrm{~nm})$ may be an important reason for preventing the penetration of larger oil molecules. 


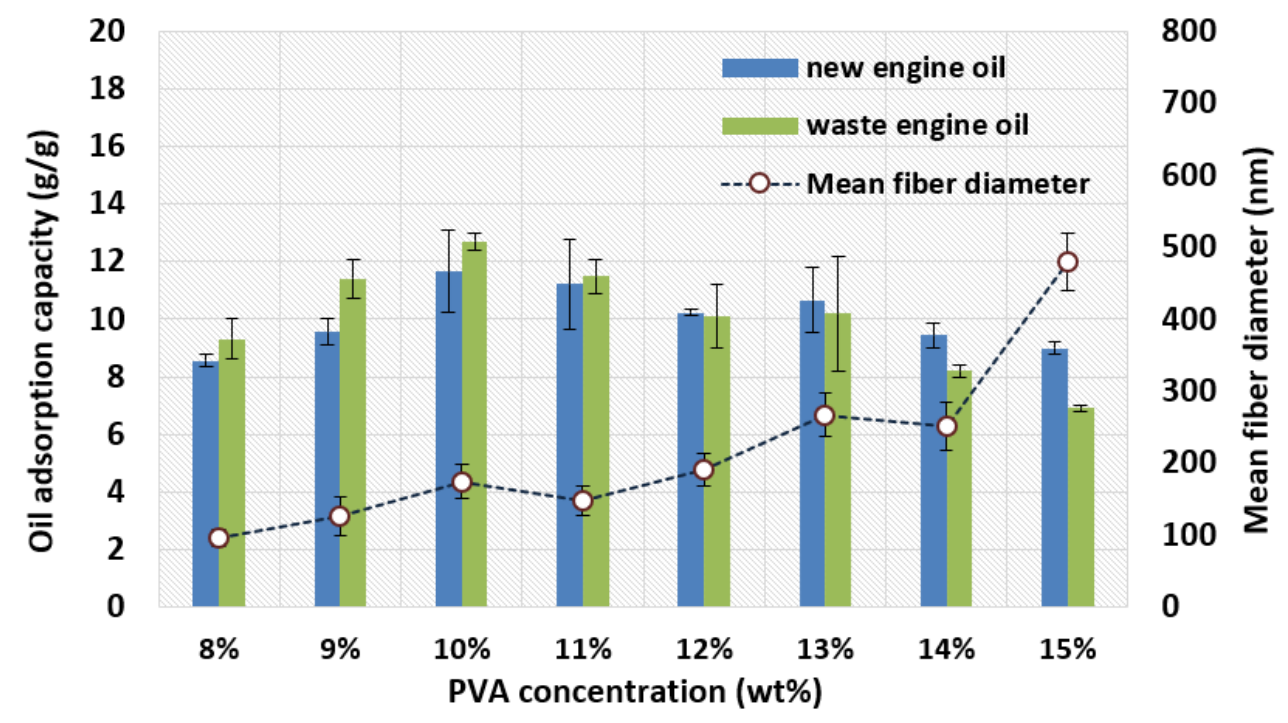

Figure 8. Oil adsorption capacities for various PVA membranes.

A $9 \mathrm{wt} \%$ PVA membrane with a larger pore size of $19.87 \mathrm{~nm}$ can absorb oil droplets whose diameters are larger, but cannot retain oil droplets whose diameters are smaller than $19.87 \mathrm{~nm}$, because small oil droplets pass through the membrane with large pore size [54]. Thus, a $10 \mathrm{wt} \%$ PVA membrane has a relatively large BET surface area $\left(12.05 \mathrm{~m}^{2} / \mathrm{g}\right)$ and pore volume $\left(0.04 \mathrm{~cm}^{3} / \mathrm{g}\right)$, and an appropriate pore size $(13.69 \mathrm{~nm})$ may be an important reason for its maximum oil adsorption capacity.

Sarbatly et al. [55] also emphasized the importance of a proper pore size of polymer nanofibers for oil adsorption. In addition, the adsorption of these two oils by the PVA membranes is also related to the viscosity of the oil. After testing, the viscosities of the new and waste engine oils were 247.96 and $281.10 \mathrm{cP}$, respectively. When the PVA concentration is less than $11 \%$, the PVA membranes have a smaller fiber diameter $(<180 \mathrm{~nm})$ and more easily promote the adhesion and penetration of high-viscosity oil due to the significant number of interconnected voids in the thinner fibers. By contrast, when the PVA concentration exceeds $11 \mathrm{wt} \%$, the larger diameter fibers form larger gaps between fibers, resulting in lower oil sorption capacity. Similar results were reported by Wu et al. [35], Chen et al. [33], and Lin et al. [56].

Therefore, the adsorption mechanism of the PVA membrane on engine oil can be summarized as follows: (i) the existence of nanofibers makes the adsorption and capillary action dominant; (ii) the diameter and pore diameter of the fiber have a certain selectivity for oil adsorption, and the oils with higher viscosity more easily adhere to and penetrate into the surface of fibers with a porous structure and small diameter; (iii) the PVA membrane has excellent lipophilic properties, provides strong adhesion, and allows more oil droplets to approach the membrane surface; (iv) when the oil droplets contact with PVA membrane surface, the nanopores on each PVA fiber provide more space for oil adsorption, and the micropores between the fibers provide more channels for oil penetration; and (v) a PVA fibrous membrane has a porous structure and provides more volume for oil storage.

\subsection{Oil Contact Angle}

To further study the lipophilic properties of the PVA membrane toward new and waste engine oils, at the 11th second after the oil droplet is dropped from the needle, captured by a high-speed camera, the contact angle between the oil droplet and the panel was measured with ImageJ software three times on each side. Selected optical micrographs of the oil droplets are shown in Figures 9-11 for the variation of the oil contact angle with different PVA concentrations. 


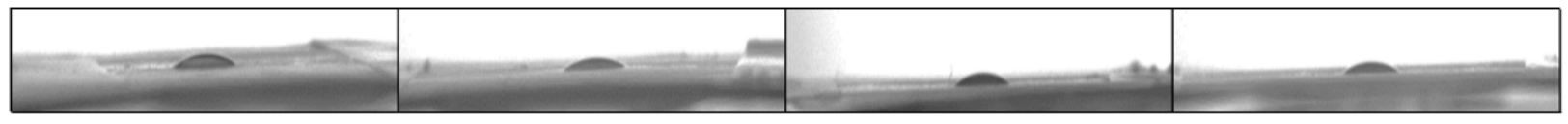
(a)
(b)
(c)
(d)

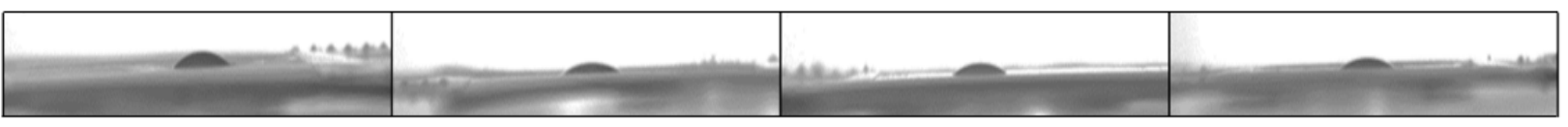
(e)
(f)
(g)
(h)

Figure 9. Optical micrographs of the new engine oil droplets; $(\mathbf{a}-\mathbf{h})$ represents the PVA solution concentration from $8 \%$ to $15 \%$, respectively.

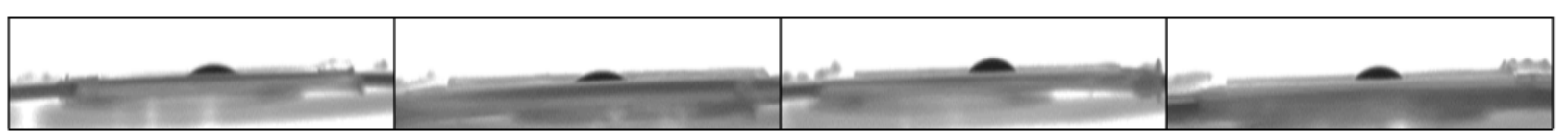
(a)
(b)
(c)
(d)

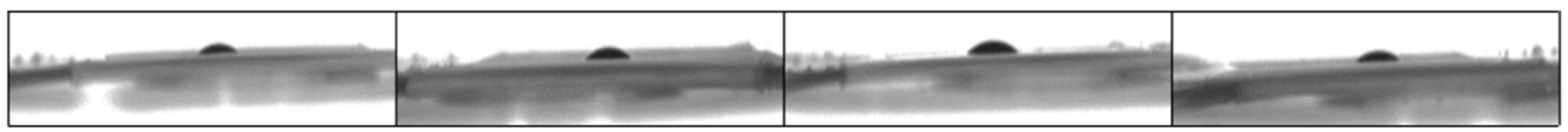
(e)
(f)
(g)
(h)

Figure 10. Optical micrographs of the waste engine oil droplets; $(\mathbf{a}-\mathbf{h})$ represents the PVA solution concentration from $8 \%$ to $15 \%$, respectively.

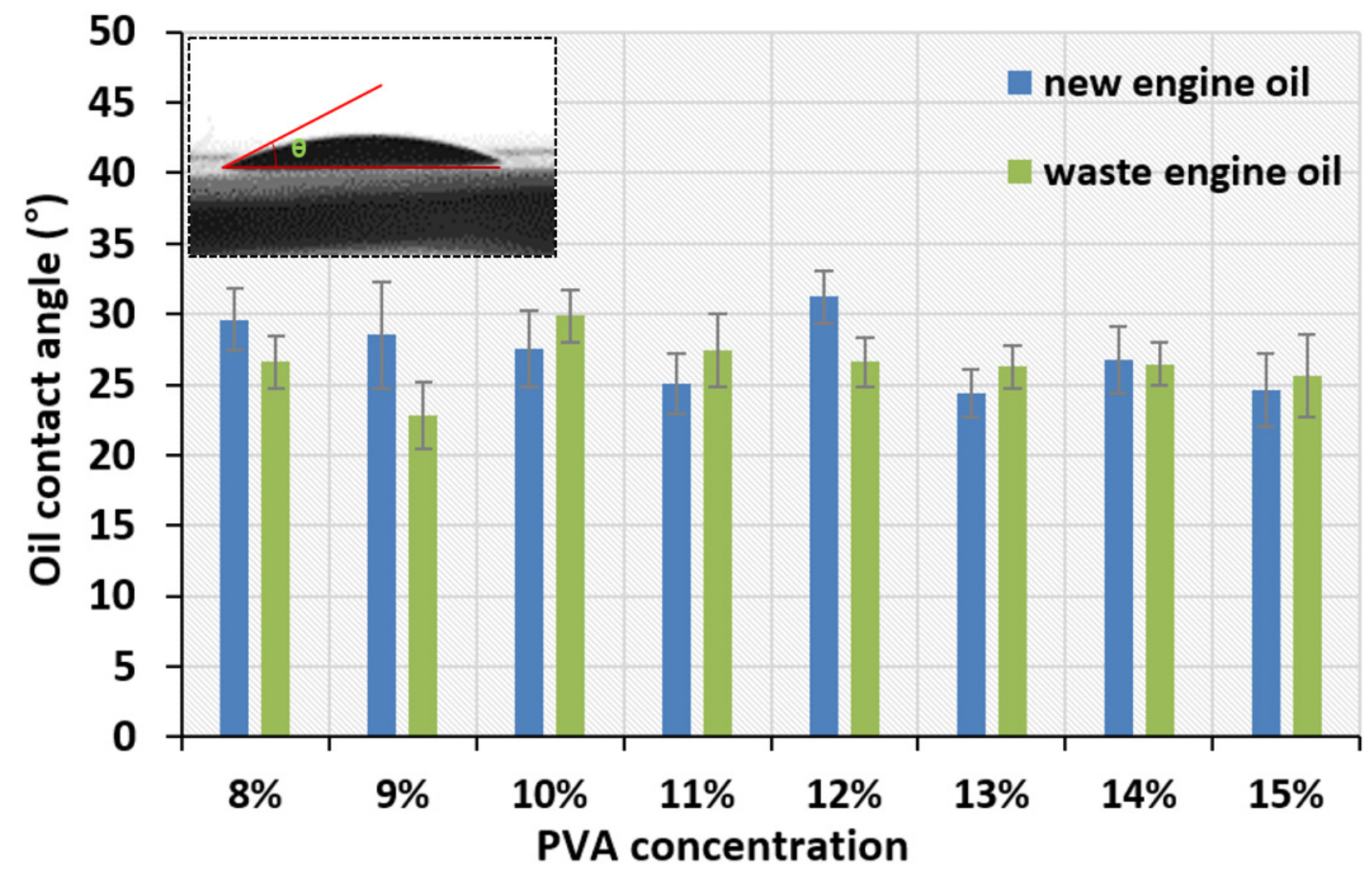

Figure 11. Oil contact angles for all tested PVA membranes. 
As shown in Figure 11, all the oil contact angles are about $30^{\circ}$ much less than $90^{\circ}$, which indicates that the electrospun PVA membrane has good lipophilicity. A superoleophilic surface is defined as a surface whose oil contact angle is close to $0^{\circ}$ [23]. From Figure 11, the concentration of the PVA electrospinning solution has almost no influence on the contact angle value, because almost all the contact angles vary between $25^{\circ}$ and $30^{\circ}$. A similar criterion was also proposed by [57]. However, when the PVA concentration exceeds $13 \mathrm{wt} \%$, the oil contact angle of the PVA membrane seems to stabilize, showing a relatively low oil contact angle.

The larger void spaces formed by large-sized fibers are beneficial to the initial penetration of oil. Moreover, the surface morphology and pore size of PVA nanofiber membrane also seems to play a crucial role in the influence of oil contact angle. $9 \mathrm{wt} \%$ and $15 \mathrm{wt} \%$ PVA nanofiber membrane have relatively large average fiber diameter, $19.87 \mathrm{~nm}$ and $17.30 \mathrm{~nm}$, respectively. Therefore, most of oil droplets can easily pass through these large pores, resulting in relatively small oil contact angles. Other studies have also reported that the surface roughness of the nanofibers and air pockets is the main factor affecting the contact angle, and adding $\mathrm{SiO}_{2}$ nanoparticles into the spinning solution is beneficial to improve the fiber surface roughness $[58,59]$.

\section{Conclusions}

In summary, eight different environmentally friendly polyvinyl alcohol (PVA) nanofibrous membranes were successfully fabricated via one-step electrospinning technology. To optimize the effect of the PVA concentration on the properties of the electrospun fibrous PVA membranes, the fiber morphology, the adsorption capacity of new and waste engine oils, and the oil contact angles were investigated and compared. Although the PVA membranes could be successfully prepared when the PVA concentrations were between $8 \mathrm{wt} \%$ and $15 \mathrm{wt} \%$, undesirable beaded fiber and agglomerate structures were formed, respectively, when the PVA concentration was lower than $9 \mathrm{wt} \%$ or more than $14 \mathrm{wt} \%$.

The $10 \mathrm{wt} \%$ PVA membrane had the highest oil adsorption capacity for new and waste engine oils. The oil adsorption capacity of the PVA membrane mainly depended on physical adsorption, which had a direct relationship with the pore size and the BET specific surface area. The oil contact angle of almost all PVA membranes was lower than $30^{\circ}$, indicating that the PVA membranes had excellent lipophilic properties. Based on the fiber morphology, pore size, BET surface area, and oil adsorption capacity, the electrospun membrane containing $10 \%$ PVA performed the best.

Author Contributions: Conceptualization, J.C.G.; methodology, J.C.G., G.W. and S.K.Y.; validation, M.S.K. and N.J.C.; formal analysis, J.C.G.; investigation, J.C.G.; data curation, J.C.G., G.W. and S.K.Y.; writing-original draft preparation, J.C.G.; funding acquisition, J.C.G. and N.J.C. All authors have read and agreed to the published version of the manuscript.

Funding: This research was supported by the Basic Science Research Program through the National Research Foundation of Korea (NRF) funded by the Ministry of Education (No. 2019R1I1A1A01057727, and No. 2021R1I1A3056655).

Institutional Review Board Statement: Not applicable.

Informed Consent Statement: Not applicable.

Data Availability Statement: Not applicable.

Conflicts of Interest: The authors declare no conflict of interest.

\section{References}

1. Bhardwaj, N.; Kundu, S.C. Electrospinning: A fascinating fiber fabrication technique. Biotechnol. Adv. 2010, $28,325-347$. [CrossRef] [PubMed]

2. Zheng, Y. 3-Fabrication on bioinspired surfaces. In Bioinspired Design of Materials Surfaces; Zheng, Y., Ed.; Elsevier: Amsterdam, The Netherlands, 2019; pp. 99-146. [CrossRef] 
3. Wen, Q.; Di, J.; Zhao, Y.; Wang, Y.; Jiang, L.; Yu, J. Flexible inorganic nanofibrous membranes with hierarchical porosity for efficient water purification. Chem. Sci. 2013, 4, 4378-4382. [CrossRef]

4. Kishan, A.P.; Cosgriff-Hernandez, E.M. Recent advancements in electrospinning design for tissue engineering applications: A review. J. Biomed. Mater. Res. Part A 2017, 105, 2892-2905. [CrossRef] [PubMed]

5. Katsogiannis, K.A.G.; Vladisavljevic, G.T.; Georgiadou, S.; Rahmani, R. Assessing the increase in specific surface area for electrospun fibrous network due to pore induction. ACS Appl. Mater. Interfaces 2016, 8, 29148-29154. [CrossRef] [PubMed]

6. Im, J.S.; Kang, S.C.; Lee, S.-H.; Lee, Y.-S. Improved gas sensing of electrospun carbon fibers based on pore structure, conductivity and surface modification. Carbon 2010, 48, 2573-2581. [CrossRef]

7. Lee, K.J.; Shiratori, N.; Lee, G.H.; Miyawaki, J.; Mochida, I.; Yoon, S.-H.; Jang, J. Activated carbon nanofiber produced from electrospun polyacrylonitrile nanofiber as a highly efficient formaldehyde adsorbent. Carbon 2010, 48, 4248-4255. [CrossRef]

8. Qin, X.H.; Wang, S.Y. Filtration properties of electrospinning nanofibers. J. Appl. Polym. Sci. 2006, 102, 1285-1290. [CrossRef]

9. He, T.; Zhou, W.; Bahi, A.; Yang, H.; Ko, F. High permeability of ultrafiltration membranes based on electrospun PVDF modified by nanosized zeolite hybrid membrane scaffolds under low pressure. Chem. Eng. J. 2014, 252, 327-336. [CrossRef]

10. Wang, X.; Min, M.; Liu, Z.; Yang, Y.; Zhou, Z.; Zhu, M.; Chen, Y.; Hsiao, B.S. Poly (ethyleneimine) nanofibrous affinity membrane fabricated via one step wet-electrospinning from poly (vinyl alcohol)-doped poly (ethyleneimine) solution system and its application. J. Membr. Sci. 2011, 379, 191-199. [CrossRef]

11. Serbezeanu, D.; Popa, A.M.; Stelzig, T.; Sava, I.; Rossi, R.M.; Fortunato, G. Preparation and characterization of thermally stable polyimide membranes by electrospinning for protective clothing applications. Text. Res. J. 2015, 85, 1763-1775. [CrossRef]

12. Teixeira, M.A.; Amorim, M.T.P.; Felgueiras, H.P. Poly (vinyl alcohol)-based nanofibrous electrospun scaffolds for tissue engineering applications. Polymers 2020, 12, 7. [CrossRef]

13. Sun, Y.; Cheng, S.; Lu, W.; Wang, Y.; Zhang, P.; Yao, Q. Electrospun fibers and their application in drug controlled release, biological dressings, tissue repair, and enzyme immobilization. RSC Adv. 2019, 9, 25712-25729. [CrossRef]

14. Chen, S.; Li, R.; Li, X.; Xie, J. Electrospinning: An enabling nanotechnology platform for drug delivery and regenerative medicine. Adv. Drug Deliv. Rev. 2018, 132, 188-213. [CrossRef]

15. Li, X.; Chen, W.; Qian, Q.; Huang, H.; Chen, Y.; Wang, Z.; Chen, Q.; Yang, J.; Li, J.; Mai, Y.W. Electrospinning-based strategies for battery materials. Adv. Energy Mater. 2021, 11, 2000845. [CrossRef]

16. Lu, L.; Yang, B.; Zhai, Y.; Liu, J. Electrospinning core-sheath piezoelectric microfibers for self-powered stitchable sensor. Nano Energy 2020, 76, 104966. [CrossRef]

17. Nikmaram, N.; Roohinejad, S.; Hashemi, S.; Koubaa, M.; Barba, F.J.; Abbaspourrad, A.; Greiner, R. Emulsion-based systems for fabrication of electrospun nanofibers: Food, pharmaceutical and biomedical applications. RSC Adv. 2017, 7, 28951-28964. [CrossRef]

18. Pant, H.R.; Kim, H.J.; Joshi, M.K.; Pant, B.; Park, C.H.; Kim, J.I.; Hui, K.S.; Kim, C.S. One-step fabrication of multifunctional composite polyurethane spider-web-like nanofibrous membrane for water purification. J. Hazard. Mater. 2014, $264,25-33$. [CrossRef] [PubMed]

19. Bazargan, A.M.; Keyanpour-Rad, M.; Hesari, F.A.; Ganji, M.E. A study on the microfiltration behavior of self-supporting electrospun nanofibrous membrane in water using an optical particle counter. Desalination 2011, 265, 148-152. [CrossRef]

20. Park, J.Y.; Lee, I.H.; Bea, G.N. Optimization of the electrospinning conditions for preparation of nanofibers from polyvinylacetate (PVAc) in ethanol solvent. J. Ind. Eng. Chem. 2008, 14, 707-713. [CrossRef]

21. Kang, D.H.; Kang, H.W. Surface energy characteristics of zeolite embedded PVDF nanofiber films with electrospinning process. Appl. Surf. Sci. 2016, 387, 82-88. [CrossRef]

22. Cui, J.; Lu, T.; Li, F.; Wang, Y.; Lei, J.; Ma, W.; Zou, Y.; Huang, C. Flexible and transparent composite nanofibre membrane that was fabricated via a "green" electrospinning method for efficient particulate matter 2.5 capture. J. Colloid Interface Sci. 2021, 582, 506-514. [CrossRef]

23. Qing, W.; Shi, X.; Deng, Y.; Zhang, W.; Wang, J.; Tang, C.Y. Robust superhydrophobic-superoleophilic polytetrafluoroethylene nanofibrous membrane for oil/water separation. J. Membr. Sci. 2017, 540, 354-361. [CrossRef]

24. Qin, X.H.; Wang, S.Y. Electrospun nanofibers from crosslinked poly (vinyl alcohol) and its filtration efficiency. J. Appl. Polym. Sci. 2008, 109, 951-956. [CrossRef]

25. Li, X.; Yang, W.; Li, H.; Wang, Y.; Bubakir, M.M.; Ding, Y.; Zhang, Y. Water filtration properties of novel composite membranes combining solution electrospinning and needleless melt electrospinning methods. J. Appl. Polym. Sci. 2015, 132, 41601. [CrossRef]

26. Horiike, S.; Matsuzawa, S.; Yamaura, K. Preparation of chemically crosslinked gels with maleate-denatured poly (vinyl alcohol) and its application to drug release. J. Appl. Polym. Sci. 2002, 84, 1178-1184. [CrossRef]

27. Pisuchpen, T.; Chaim-Ngoen, N.; Intasanta, N.; Supaphol, P.; Hoven, V.P. Tuning hydrophobicity and water adhesion by electrospinning and silanization. Langmuir 2011, 27, 3654-3661. [CrossRef]

28. Zhu, M.; Xiong, R.; Huang, C. Bio-based and photocrosslinked electrospun antibacterial nanofibrous membranes for air filtration. Carbohydr. Polym. 2019, 205, 55-62. [CrossRef]

29. Pervez, M.; Stylios, G.K. Investigating the synthesis and characterization of a novel "green" $\mathrm{H}_{2} \mathrm{O}_{2}$-assisted, water-soluble chitosan/polyvinyl alcohol nanofiber for environmental end uses. Nanomaterials 2018, 8, 395. [CrossRef]

30. Zhang, S.; Shi, Q.; Christodoulatos, C.; Korfiatis, G.; Meng, X. Adsorptive filtration of lead by electrospun PVA/PAA nanofiber membranes in a fixed-bed column. Chem. Eng. J. 2019, 370, 1262-1273. [CrossRef] 
31. Zhu, M.; Hua, D.; Pan, H.; Wang, F.; Manshian, B.; Soenen, S.J.; Xiong, R.; Huang, C. Green electrospun and crosslinked poly (vinyl alcohol)/poly (acrylic acid) composite membranes for antibacterial effective air filtration. J. Colloid Interface Sci. 2018, 511, 411-423. [CrossRef]

32. Zhang, D.; Jin, X.-Z.; Huang, T.; Zhang, N.; Qi, X.-D.; Yang, J.-H.; Zhou, Z.-W.; Wang, Y. Electrospun fibrous membranes with dual-scaled porous structure: Super hydrophobicity, super lipophilicity, excellent water adhesion, and anti-icing for highly efficient oil adsorption/separation. ACS Appl. Mater. Interfaces 2019, 11, 5073-5083. [CrossRef] [PubMed]

33. Chen, P.-Y.; Tung, S.-H. One-step electrospinning to produce nonsolvent-induced macroporous fibers with ultrahigh oil adsorption capability. Macromolecules 2017, 50, 2528-2534. [CrossRef]

34. Sambudi, N.S.; Kim, M.G.; Park, S.B. The formation of web-like connection among electrospun chitosan/PVA fiber network by the reinforcement of ellipsoidal calcium carbonate. Mater. Sci. Eng. C 2016, 60, 518-525. [CrossRef] [PubMed]

35. Wu, J.; Wang, N.; Wang, L.; Dong, H.; Zhao, Y.; Jiang, L. Electrospun porous structure fibrous film with high oil adsorption capacity. ACS Appl. Mater. Interfaces 2012, 4, 3207-3212. [CrossRef] [PubMed]

36. Wen, P.; Zhu, D.-H.; Wu, H.; Zong, M.-H.; Jing, Y.-R.; Han, S.-Y. Encapsulation of cinnamon essential oil in electrospun nanofibrous film for active food packaging. Food Control. 2016, 59, 366-376. [CrossRef]

37. Angel, N.; Guo, L.; Yan, F.; Wang, H.; Kong, L. Effect of processing parameters on the electrospinning of cellulose acetate studied by response surface methodology. J. Agric. Food Res. 2020, 2, 100015. [CrossRef]

38. Haider, A.; Haider, S.; Kang, I.-K. A comprehensive review summarizing the effect of electrospinning parameters and potential applications of nanofibers in biomedical and biotechnology. Arab. J. Chem. 2018, 11, 1165-1188. [CrossRef]

39. Sill, T.J.; Von Recum, H.A. Electrospinning: Applications in drug delivery and tissue engineering. Biomaterials 2008, 29, 1989-2006. [CrossRef]

40. Wang, T.; Kumar, S. Electrospinning of polyacrylonitrile nanofibers. J. Appl. Polym. Sci. 2006, 102, 1023-1029. [CrossRef]

41. Megelski, S.; Stephens, J.S.; Chase, D.B.; Rabolt, J.F. Micro-and nanostructured surface morphology on electrospun polymer fibers. Macromolecules 2002, 35, 8456-8466. [CrossRef]

42. Santos, C.; Silva, C.J.; Büttel, Z.; Guimarães, R.; Pereira, S.B.; Tamagnini, P.; Zille, A. Preparation and characterization of polysaccharides/PVA blend nanofibrous membranes by electrospinning method. Carbohydr. Polym. 2014, 99, 584-592. [CrossRef] [PubMed]

43. Koski, A.; Yim, K.; Shivkumar, S. Effect of molecular weight on fibrous PVA produced by electrospinning. Mater. Lett. 2004, 58, 493-497. [CrossRef]

44. Zhang, C.; Yuan, X.; Wu, L.; Han, Y.; Sheng, J. Study on morphology of electrospun poly (vinyl alcohol) mats. Eur. Polym. J. 2005, 41, 423-432. [CrossRef]

45. Wang, G.; Xiao, W.; Yu, J. High-efficiency dye-sensitized solar cells based on electrospun $\mathrm{TiO}_{2}$ multi-layered composite film photoanodes. Energy 2015, 86, 196-203. [CrossRef]

46. Kim, C.H.; Kim, B.-H.; Yang, K.S. $\mathrm{TiO}_{2}$ nanoparticles loaded on graphene/carbon composite nanofibers by electrospinning for increased photocatalysis. Carbon 2012, 50, 2472-2481. [CrossRef]

47. Peng, S.; Zhou, M.; Liu, F.; Zhang, C.; Liu, X.; Liu, J.; Zou, L.; Chen, J. Flame-retardant polyvinyl alcohol membrane with high transparency based on a reactive phosphorus-containing compound. R. Soc. Open Sci. 2017, 4, 170512. [CrossRef]

48. Kurd, F.; Fathi, M.; Shekarchizadeh, H. Basil seed mucilage as a new source for electrospinning: Production and physicochemical characterization. Int. J. Biol. Macromol. 2017, 95, 689-695. [CrossRef]

49. Na, H.; Chen, P.; Wong, S.-C.; Hague, S.; Li, Q. Fabrication of PVDF/PVA microtubules by coaxial electrospinning. Polymer 2012, 53, 2736-2743. [CrossRef]

50. Alhosseini, S.N.; Moztarzadeh, F.; Mozafari, M.; Asgari, S.; Dodel, M.; Samadikuchaksaraei, A.; Kargozar, S.; Jalali, N. Synthesis and characterization of electrospun polyvinyl alcohol nanofibrous scaffolds modified by blending with chitosan for neural tissue engineering. Int. J. Nanomed. 2012, 7, 25.

51. Kharazmi, A.; Faraji, N.; Hussin, R.M.; Saion, E.; Yunus, W.M.M.; Behzad, K. Structural, optical, opto-thermal and thermal properties of ZnS-PVA nanofluids synthesized through a radiolytic approach. Beilstein J. Nanotechnol. 2015, 6, 529-536. [CrossRef]

52. Bhat, N.; Nate, M.; Kurup, M.; Bambole, V.; Sabharwal, S. Effect of $\gamma$-radiation on the structure and morphology of polyvinyl alcohol films. Nucl. Instrum. Methods Phys. Res. Sect. B Beam Interact. Mater. At. 2005, 237, 585-592. [CrossRef]

53. Zhu, H.; Qiu, S.; Jiang, W.; Wu, D.; Zhang, C. Evaluation of electrospun polyvinyl chloride/polystyrene fibers as sorbent materials for oil spill cleanup. Environ. Sci. Technol. 2011, 45, 4527-4531. [CrossRef] [PubMed]

54. Qing, W.; Li, X.; Wu, Y.; Shao, S.; Guo, H.; Yao, Z.; Chen, Y.; Zhang, W.; Tang, C.Y. In situ silica growth for superhydrophilicunderwater superoleophobic Silica/PVA nanofibrous membrane for gravity-driven oil-in-water emulsion separation. J. Membr. Sci. 2020, 612, 118476. [CrossRef]

55. Sarbatly, R.; Krishnaiah, D.; Kamin, Z. A review of polymer nanofibres by electrospinning and their application in oil-water separation for cleaning up marine oil spills. Mar. Pollut. Bull. 2016, 106, 8-16. [CrossRef] [PubMed]

56. Lin, J.; Shang, Y.; Ding, B.; Yang, J.; Yu, J.; Al-Deyab, S.S. Nanoporous polystyrene fibers for oil spill cleanup. Mar. Pollut. Bull. 2012, 64, 347-352. [CrossRef]

57. Obaid, M.; Barakat, N.A.; Fadali, O.; Motlak, M.; Almajid, A.A.; Khalil, K.A. Effective and reusable oil/water separation membranes based on modified polysulfone electrospun nanofiber mats. Chem. Eng. J. 2015, 259, 449-456. [CrossRef] 
58. Yang, Y.; Li, Y.; Cao, L.; Wang, Y.; Li, L.; Li, W. Electrospun PVDF-SiO 2 nanofibrous membranes with enhanced surface roughness for oil-water coalescence separation. Sep. Purif. Technol. 2021, 269, 118726. [CrossRef]

59. Kakunuri, M.; Wanasekara, N.D.; Sharma, C.S.; Khandelwal, M.; Eichhorn, S.J. Three-dimensional electrospun micropatterned cellulose acetate nanofiber surfaces with tunable wettability. J. Appl. Polym. Sci. 2017, 134, 15. [CrossRef] 